\title{
What Drives Continued Intention for Mobile Payment? - An Expectation Cost Benefit Theory with Habit
}

\author{
Kuan-Yu Lin \\ Ling Tung University \\ ntustmislab@gmail.com
}

\author{
Yi-Ting Wang \\ Ling Tung University \\ yw7@umail.iu.edu
}

\author{
Travis K. Huang \\ Ling Tung University \\ travisk.huang@gmail.com
}

\begin{abstract}
The number of smartphone users has increased rapidly in recent years as the mobile networking becomes more mature, which not only gives rise to a new lifestyle but also facilitates the development of mobile application services. Smartphones thus become an indispensable device of people's daily contact. Today people from all walks of life set their attention on mobile payments amongst smartphone mobile application services. To explore the factors affecting users' continued use of mobile payments, this study has sought to build a theoretical framework based on the cost-benefit theory and add habit as a factor to put forward an integrated research model, which explicates people's continued use of mobile payment services. An online questionnaire was employed to collect empirical data. A total of 295 samples were analyzed using structural equation modeling (SEM) approach. The results showed that both perceived value and habit played an important role in users' continued intention to use mobile payment services. Also, the perceived benefits (mobile convenience and service compatibility) and perceived costs (security risk and perceived fee) are crucial factors that determine users' perceived value. In addition, the study also found that perceived value had a positive impact on users' habit, showing that in the context of a mobile-oriented information system, whether mobile payment services satisfied users' perceived value influenced the formation of habit of using such services. The implications of these findings are discussed.
\end{abstract}

\section{Introduction}

Having rapidly become popular, smartphones, along with the fully developed mobile network, not only bring new lifestyles centering on mobile devices but also boost the development of other mobile application services like mobile payments. Smartphones have undoubtedly become an important tool of daily communication. In recent years, people from all walks of life have paid attention to mobile payments amongst smartphone mobile application services [1]. Mobile payment service means that a consumer takes a mobile device (such as Smartphones) as a carrier. When sending payment, a consumer could use non-cash financial instrument through a specific transfer technology, device or network coupled with verification processes. The transaction payment would be complete and goods or services would be obtained in a bricks and mortar location. (e.g., Wireless Application Protocol, Unstructured Supplementary Service Data, short messaging services, and General Packet Radio Service) [2]. In other words, the service for payment would be in progress through consumers' mobile devices. In the absence of cash, checks or credit cards, consumers can use mobile devices to pay for any services or commodities in digital and bricks and mortar location. [3]. According to the Statistic [4] survey, the total number of mobile payment users worldwide in 2015 was 384 million and is expected to reach 450 million in 2017. And the transaction of mobile payments will grow from US $\$ 450$ billion in 2015 to US\$780 billion in 2017 and is expected to reach US\$ 1080 billion in 2019. Apparently, both the number of users and the market size are increasing year after year. Nielsen [5] found that users' commonly used payment service applications were dining (49\%), entertainment $(43 \%)$, shopping $(39 \%)$, payment $(36 \%)$, traffic $(36 \%)$, leasing (19\%), etc. Also, approximately $40 \%$ of the users expressed their follow-up intention to use mobile payment as the main way of consumption afterwards. The use of mobile payments has attracted the public's attention successfully, and the market of mobile payments is assumed to be a business full of potential. Understanding factors which encourage users to use mobile payments is very important to providers of mobile payment services. Thus this study seeks to examine the factors that affect users' acceptance of mobile payments.

According to the cost-benefit theory, when adopting the information system, users would take into consideration the necessary expenses or effort cost, in addition to the benefits created by the use of such system. After users compare the benefits and costs, 
perceived value is formed, which further affects their intention to use [6][7]. Zeithaml [8] defined perceived value as the assessment of the total effect of a product or service on consumers who purchase the product or service after they perceive what they have given and what they have received. Based on the foregoing, the perceived value of users is subject to certain products or services [8]. The analyses of product and service attributes (both positive and negative) lead to a better understanding of formation of consumer value [6][9][10][11].

In this study, the mobile payment service has its positive and negative characteristics, for the positive, such as convenience in time, accessing and use; in other words, compared to the off-line payment (e.g., paper money, credit cards), users can obtain the conveniences, such as quickly pay, provide the purchase information records via smartphones In addition, mobile payment also has service compatibility, users can engage in the same way as offline payment compatible services. For the negative, Tan et al., [2] stated that the perceived cost of the user's action of mobile payment services, includes currency and non-monetary. Numerous scholars [2][9] pointed out that, when the user uses the mobile payment, the monetary cost paid includes the access fee, the transaction fee, etc., and the non-monetary cost includes perceived risks such as the user's personal information, privacy and security. This study suggests that the attributes of these mobile payment services are related to Rogers' [12] perceived characteristics of innovations (PCI) framework, such as relative advantage, compatibility and complexity. This study is, therefore, to understand the service attributes of mobile value brought about by pushing mobile payments forward based upon the viewpoint on perceived innovation characteristics.

In addition, the studies on information systems [13][14][15] argued that habit played a very important role in affecting individuals' use of information systems. It has been argued that the stronger the habit that customers have, the less willing they are to take into account options other than the existing information systems, and hence the lower customers' intention to replace the information systems would be [13][16]. Hsiao et al. [17] further pointed out that customers would develop a habit as a result of their continued use of such information systems because of the rise of customer value perception. From the viewpoint of the above-mentioned scholars, this study combines costbenefit theory, perceived value, and habit to propose a research model to explain why people continue to use the mobile payment systems. Through this study, the following relevant questions were answered:

RQ1. What are the key cost-benefit characteristic factors of mobile payment systems that lead to users' perceived value?

RQ2. What is the key factor affecting users' intention to continually use mobile payment systems?

\section{Literature review}

In the information system literature discussing people's usage behaviors, two theories are widely applied [18], namely the technology acceptance model (TAM) [19] and the unified theory of acceptance and use of technology (UTAUT)[20]. Subsequent research [11][21][22][23] based on the same theory explores users intentions to use mobile value-added services. However, recent studies into mobile technology services have introduced the perspective of value in the research context, with perceived value being one of the chief issues. That is, researchers took the approach of determining the value of products or services as perceived by users, which is more pertinent to the user's mind [24][25]. Numerous scholars [17][25] believed that perceived value is important to mobile technology users, and is a reason for users continuing to use mobile payment systems. Perceived value is the tradeoff between benefits and costs [6][8][24]. In addition, many empirical studies [16][17] believed it is necessary to incorporate the factors of habit in the exploration of influence on the individual's intention to use mobile technology. In summarizing the abovestated views of researchers, we combine the costbenefit theory, perceived value, and habit, hoping to propose an integrated research model to describe the reasons why people continue to use the mobile payment systems.

\subsection{Cost benefit theory}

Cost benefit is defined as a decision in which people tend to pursue the maximum benefit and the least cost subject to the benefit produced and the cost necessarily paid arising from the behavior taken into account when making decisions [7][10]. Some scholars [6][7] suggested that users tend to develop a perceived value which affects the willingness to use the products or services after comparing the benefit produced with the cost necessarily paid arising from the products or services. In other words, when making decisions that involve an action adoption, users would think about the cost (monetary and non-monetary) required after use. After comparing the benefits and costs, there will be perceived value for the service or the product, and the resulting value perception will affect their willingness to use the service or product [10][11]. Many studies have indicated that users' willingness to adopt the information system will be influenced by the 
comparison between benefits and costs, and consequently the most favorable information system for them will be used [6][7][8].

\subsection{Perceived value}

The formation of the value in the customer's mind is a total utility assessment of the product or service based on the results of the cognitive process of comparison [8]. Different contexts may affect the basic ingredients necessary for the customer's perceived value. The concept of the most-frequently used definition of value is the specific value of "quality" and "price" or the consequence of the choices [8]. However, some scholars pointed out that regarding value as a measure between quality and price was too simplistic [26]. To measure customers' overall value by using a single item alone will lead to a lack of validity [25][27], and will not reflect the general belief in the literature that "perceived value is a substitute relationship between giving and receiving". Many scholars in the follow-up period [6][10][11][25], based on a costbenefit point of view, extended the measurement constructs of perceived value according to the study of the situation. Kim et al. [6] measured perceived values by using perceived usefulness, perceived entertainment, technology perceived ease of use and perceived fees, and probed into the impact of users' usage intention on mobile networks. The study found that the user's perceived usefulness, perceived entertainment, technology perceived ease of use and the perception of costs would signify perceived value, and the perceived value would further significantly affect the user's behavior intentions. Lin and $\mathrm{Lu}$ [25] explored the perceived value affecting users on mobile technology by using mobile convenience, service compatibility, security risk and cognitive effort. The study found that all these four dimensions affect the perceived value in the user's mind.

The above literature has shown that the value of different dimensions affects users' decision in different decision situations, products, and services. Value is a constant belief that individuals would prefer a particular behavior or lifestyle based on such belief [27]. In addition, value affects personal attitudes and behavior, for occurrence of personal behavior behind which the reason is often to achieve the pursuit of a certain value [17]. Many scholars have pointed out that perceived value has a direct and significant influence on customer behavioral intentions [6][7][10] [13][25][27]. Thus, this study will take into account the characteristics of the mobile commerce situation to examine the impact of users' perceived value formed upon mobile payment services on the willingness to use the payment service.

\subsection{Habit}

Aarts and Dijksterhuis [28] claimed that habit was an act that automatically indicated a goal at a spiritual level. Limaye and Hirt [29] argued that habit could reflect an individual's developed and accumulated automatic behavioral tendencies in the past. In other words, people would usually continue to use their way to carry out certain tasks without thinking deeply about the tasks. It is mainly because of habits. Limayem et al. [15] further pointed out that people would unconsciously perform a certain behavior on account of the results of repeated previous studies The concept of habit in the study of information technology related issues has been widely cited and used in the interpretation and validation theory predicting individual behavior patterns, and many studies have also shown that habit used to explain and predict the behavior of information system users is a crucial factor [13][15][16][17]. According to these studies, habit has played an influencing part in the use of customers' influence on the use of information systems. In view of this, the study adds habit as an independent variable to examine whether it affects the behavior intention of mobile payments.

\section{Research model and hypotheses}

Figure 1 illustrates the research model proposed in this study. Perceived value is a trade-off between the benefit and the cost [6][8][24]. In this model, it is assumed that perceived value and habit are the crucial factors, which determine the use of mobile payment services, wherein both cognitive benefits and costs affect the mobile value of the use of mobile payment services. With respect to cognitive benefits and costs, adoption process of products or services was explained through Rogers' [12] perceived characteristics of innovations (PCI) among the studies related to adoption of products or services. Rogers [12] pointed out that relative advantage, compatibility, complexity, observability and trialability are important characteristics that affect an individual's awareness of science and technology. However, research in information systems suggest that only relative advantage, compatibility, and complexity have a significant and consistent correlation with the use of products or services [25] [24]. Thus, this study will use these three traits as predictive variables of perceived benefits and perceived costs of mobile payments.

On the aspect of perceived benefits, this study takes the relative advantage and compatibility as a measurement construct. First, the most significant feature of mobile value-added services is that they are 
available anytime and anywhere, allowing users to manage their efficiently [25]. This study is based on the study of Mobile Commerce, Kleijnen et al. [24], using mobile convenience to measure the relative advantage of mobile payments. Next, the compatibility emphasizes the degree that the value-added service is compatible with the needs of consumer services [24][25], such as the consistency of the services provided online and off-line. In other words, the user can use compatibility services such as using cash or physical card paid through mobile devices the same way as in physical stores. Accordingly, this study uses service compatibility to represent Rogers' [12] compatibility construct. In terms of perceived costs, complexity will negatively affect the proliferation of innovation [12]. Complexity is the degree of difficulty in understanding and using the perceived innovation. When the user feels uncertainty about the system (such as whether or not security risks will arise during the usage), the feelings about complexity of the system is improved [25]. From the perspective of consumers, the part that the consumer must abandon or sacrifice at the time of the transaction will affect the consumer's assessment on perceived value [6][8][11], which is the cost paid in completing the transaction, that is, perceived cost. Many scholars [6][10] believe that perceived costs include monetary and non-monetary costs. Therefore, this study takes security risk (non-monetary cost) and perceived cost (monetary cost) as the cost factor for the use of mobile payment.

In the context of information systems, habit has an impact upon the relationship between the types of users' behavior [13][14][16]. Users' degree of preference for the information system is influenced by the value perception that such system provides, thereby increasing the willingness to continuously use the information system [17]. The definition and hypothesis for each construct used in the model are discussed in the following subsections.

\subsection{Perceived benefits}

\section{Mobile convenience}

Perceived benefit is one of the important factors influencing perceived value and has a positive effect on perceived values [6][10]. Perceived benefit is the advantage of the consumer's assessment of products or services. That is to say, it is the benefit that the consumer can obtain from the products or services [7][24][25].

Lin and Lu [25] highlighted the mobile commerce with timely and no-time-limited convenience services.
Kim and Hwang [30] pointed out that through mobile device like smartphones, users may collect information and conduct transactions at any time and any place by using their mobile phones. Through the timely and effective service delivery, users obtain the value of mobile value-added services brought by the convenience that mobile phones provide [10][24][25]. Wang [31] further argued that the convenience brought by mobile technology might positively affect perceived value. Based on the foregoing, this study deduces that users can use mobile payment services through smartphones to quickly, easily and efficiently complete the payment process, so that the consumers may access information, services, and meet individual needs when moving around, and additionally increase the value in users' minds. Therefore, this study hypothesizes the following:

Hypothesis la: Mobile convenience positively affects users' perceived value.

\section{Service compatibility}

Compatibility emphasizes the degree of compliance with the demand for mobile value-added services and consumer services [24][25]. Roger [12] defined compatibility as the degree to which users' sense of values, experiences and needs brought by the innovative products or services were in line with that brought by the original products or services. For example, users use community sites through computers and smartphones respectively with the same service functionality [25]. Meuter et al. [32] also argued that compatibility referred to the degree to which the product was consistent with consumer value and lifestyle. The concept of compatibility was applied to the relevant mobile technology as well [24][25]. According to the research by Kleijnen et al. [24], the main reason why consumers used mobile value-added services was to meet specific service needs, and the compatibility of mobile value-added services with specific service requirements was service compatibility. For example, users may pay for the purchase by using the mobile payment through the smartphone when making the checkout as if they were using cash or physical cards. In other words, when users perceive the technical characteristics of the service that can be served in the same way as cash or physical cards, it will satisfy their service needs and help to increase consumption value. Therefore, it is hypothesized:

Hypothesis 1b: Service compatibility positively affects users' perceived value. 


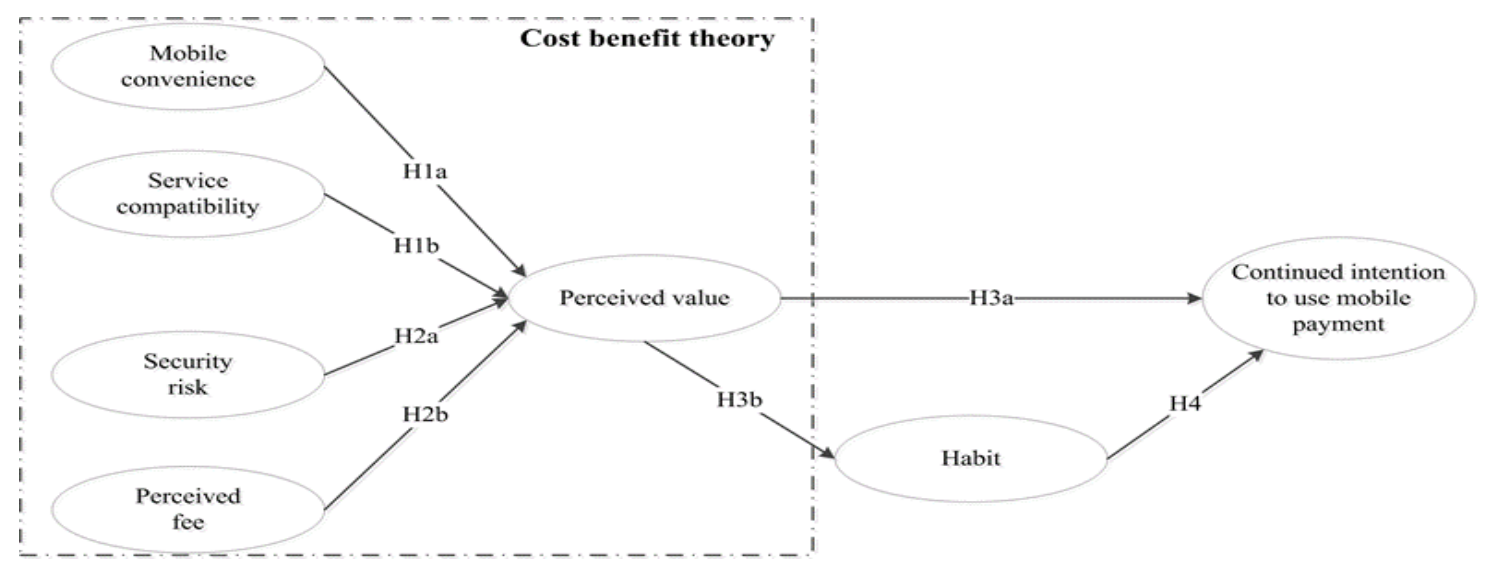

Figure 1. The Research Model

\subsection{Perceived costs}

\section{Security risk}

Several studies [10][11] have found that users using wireless networks to transmit information were always concerned that their personal information might be leaked and thus generated a doubtful risk about using mobile networks. According to the MIC [33] study, the safety issue was the first consideration when users used mobile payments, mainly because they were worried that the use of mobile payments might lead to the leak of personal information and consumption records, credit card fraud, repetitive charge or loss of mobile phones and other uncertainties. Therefore, smartphone users would also be worried about risks, such as personal privacy and data leakage during the process when using smartphones to make payments. In view of the above, the more security risks of personal information leakage that users perceive when using the mobile phone as an instrument of payment, the worse the evaluation of services provided by mobile payments would be. That is to say, consumers' perceived risk will negatively affect perceived values. Therefore, this study hypothesizes:

Hypothesis 2a: Security risk negatively affects users' perceived value.

\section{Perceived fee}

Merriam-Webster [34] defines fees as "payments made or collected for services". Perceived fee is "the cost of a customer's payment for a product or service" [4], a concept of substitution between money and value. Scholars [6][9] argued that perceived fees were monetary costs, such as transaction fees and processing fees. In other words, a buyer will take into account various aspects of cost accompanied with transactions in order to complete a market transaction. Several studies [6][10][11][33] discovered that perceived fees negatively affected users' perceived value in minds. Consumers might have to pay derived fees like transaction fees [33] in addition to the cost of products or services when paying the overall fees through the mobile payment. This study, thus, suggests that the higher the perceived fee is, the greater the cost that the consumers sacrifice would be, which may result in a lower perceived value of mobile payments. This study hypothesizes:

Hypothesis 2b: Perceived fee negatively affects users' perceived value.

\subsection{Perceived value}

As Kim et al. [6] defined the perceived value was "the process by which the user makes a total utility assessment after considering the product or service behind the behavior upon the information system perception". Studies have also shown in recent years that the perception in users' minds positively affects the behavioral willingness [6][7][25]. Hsiao et al. [17] pointed out in the Mobile Information System study that the user's value perception affects the degree of habit on such system. In other words, when the higher the total utility of such information technology that the users consider, the more their habits increase. Therefore, this study assumes that when perceiving that the mobile payment service presents a value perception, users will develop a using habit, which affects their willingness to use the system. On the basis of these facts, the following hypotheses are proposed:

Hypothesis 3a: Perceived value positively influences users' continued intention to use mobile payment.

Hypothesis 3b: Perceived value positively affects users' habit. 


\subsection{Habit}

Habit could reflect an individual's developed and accumulated automatic behavioral tendencies in the past [29]. Limaye and Hirt [15] argued that people would unconsciously perform a certain behavior on account of the results of repeated previous study. In other words, people would usually continue to use their way to carry out certain tasks without thinking deeply about the tasks merely because of habit.

A body of research in information technology [17][21][35] have shown that habit positively influences the relationship amongst various types of users' behavior in the context of information technology uses. Some scholars [17][21][35] further argued that when forming a habit of mobile technology, users would increase their willingness to use such mobile technology services. This study thus hypothesizes:

Hypothesis 4: Habit positively affects users' continued intention to use mobile payment.

\subsection{Control variables}

To examine the proposed research model, the additional control variables were added, including gender and age. Frequency of use significantly affects either technology acceptance or usage intention, whereas people of different genders and ages may have dissimilar perceptions on the intention to use mobile payment services. Therefore, these variables were expected to influence users' intention to use mobile payment value across the model.

\section{Measurement}

The research model involves seven factors. Each factor was measured with multiple items. To ensure content validity, the items selected for the constructs were largely adapted from previous research. The items were slightly modified to match the context of mobile payment. The items of mobile convenience (4 items) and service compatibility ( 3 items) were adapted from Kleijnen et al. [24], and the items of measuring security risk ( 3 items) and perceived fee ( 2 items) were adapted from Lee [36] and Luarn and Lin [37]. Mobile value (4 items) was adapted from Kim et al. [6], while the items used to measure habit (3 items) were modified from Limayem and Hirt [29]. Finally, the items measuring the intention to use mobile payment (3 items) were modified form Davis [19]. All items were measured on a five-point Likert-type scale, ranging from "strongly disagree" (1) to "strongly agree' (5). Table 1 lists all of the survey items used to measure each construct and descriptive statistics.

\section{Results}

\subsection{Data collection and sampling}

This study aims to explore the factors affecting users' intention to use mobile payment service. The target of this study is customers with mobile payment experience in Taiwan. Data were collected mainly via an online questionnaire survey. Invitation messages were posted in popular smartphone forums over a fiveweek period. A total of 368 online questionnaires were collected. After removing 54 respondents who did not use mobile payment and 14 questionnaires with invalid or repeated answers, the total number of valid questionnaires was 295 , indicating a valid return rate of 80.2 percent. $51.5 \%$ of the respondents were males and $48.5 \%$ were females. $32.9 \%$ of the respondents were aged between 26 and 35, 30.8\% were aged between 19 and $25,15.3 \%$ were under 18 , and $21 \%$ were aged 36 and over.

\subsection{Measurement model}

The measurement model was further assessed for construct reliability and validity. The reliability and validity analysis used Cronbach's alpha and composite reliability (CR), and average variance extracted (AVE). As shown in Table 1, Cronbach's alpha ranged from 0.71 to 0.91 and CR ranged from 0.71 to 0.91 ; these all exceeded the recommended score of 0.7 , indicating adequate reliability [38] [39].

Convergent validity measures whether the items used can effectively reflect their corresponding factor and whether they can be assessed by examining factor loadings, composite reliability (CR), and average variance extracted (AVE). As shown in Table 1, factor loadings (FL) of all items in the measurement model of this study exceeded 0.7. All AVEs and CRs exceed 0.5 and 0.7 , respectively. Thus, the scale has a good convergent validity [40]. Therefore, the measurement model in this study showed satisfactory reliability and convergent validity.

\subsection{Structural model}

Using AMOS 21 with maximum likelihood estimation was used to test the structural model. The model fits criteria suggested by Hayduck [41] $\left(\chi^{2} / \mathrm{df} \leqq\right.$ 3), Scott [42] (GFI $\geqq 0.9$ and AGFI $\geqq 0.8$ ), Bentler and Bonett [43] (NFI $\geqq 0.9$ ), and Bagozzi and Yi [40] (CFI $\geqq 0.9$ and $\mathrm{RMSE} \geqq 0.08$ ). 
Table 1. Statistics of Construct Items

\begin{tabular}{|c|c|c|c|c|c|}
\hline Construct and items & Indicator & FL & $\mathrm{CR}$ & AVE & Alpha \\
\hline Mobile Convenience (MC) (Adapted from Kleijnen et al. [24]) & & & 0.84 & 0.56 & 0.84 \\
\hline Using mobile payment is an efficient way to manage my time. & MC1 & 0.74 & & & \\
\hline Using mobile payment would be convenient for me. & $\mathrm{MC} 2$ & 0.77 & & & \\
\hline Using mobile payment would allow me to save time. & MC3 & 0.78 & & & \\
\hline $\begin{array}{l}\text { Using mobile payment would allow me to use service transactions } \\
\text { instantly. }\end{array}$ & MC4 & 0.70 & & & \\
\hline Service Compatibility (SC) (Adapted from Kleijnen et al. [24]) & & & 0.82 & 0.61 & 0.82 \\
\hline Using mobile payment fulfills my service needs. & $\mathrm{SC} 1$ & 0.80 & & & \\
\hline $\begin{array}{l}\text { Mobile payment is compatible with the way I normally perform } \\
\text { my service transactions. }\end{array}$ & $\mathrm{SC} 2$ & 0.80 & & & \\
\hline Mobile payment fits my service preferences. & $\mathrm{SC} 3$ & 0.74 & & & \\
\hline Security Risk (SR) (Adapted from Lee [36]) & & & 0.83 & 0.62 & 0.85 \\
\hline $\begin{array}{l}\text { I would not feel totally safe providing personal privacy } \\
\text { information over the mobile payment system. }\end{array}$ & SR1 & 0.68 & & & \\
\hline $\begin{array}{l}\text { I'm worried to use mobile payment because other people may be } \\
\text { able to access my account. }\end{array}$ & SR2 & 0.81 & & & \\
\hline $\begin{array}{l}\text { I would not feel secure sending sensitive information across the } \\
\text { mobile payment. }\end{array}$ & SR3 & 0.86 & & & \\
\hline Perceived Fee (PF) (Adapted from Luarn and Lin [37]) & & & 0.71 & 0.56 & 0.71 \\
\hline It would cost a lot to use mobile payment. & PF1 & 0.76 & & & \\
\hline $\begin{array}{l}\text { There are financial barriers (e.g., having to pay for handset and } \\
\text { communication time) to my using mobile payment. }\end{array}$ & PF2 & 0.73 & & & \\
\hline Perceived Value (MV) (Adapted from Kim et al. [6]) & & & 0.91 & 0.71 & 0.91 \\
\hline $\begin{array}{l}\text { Compared to the fee I need to pay, the use of mobile payment } \\
\text { offers good value for money. }\end{array}$ & MV1 & 0.76 & & & \\
\hline $\begin{array}{l}\text { Compared to the effort I need to put in, the use of mobile payment } \\
\text { is beneficial to me. }\end{array}$ & MV2 & 0.91 & & & \\
\hline $\begin{array}{l}\text { Compared to the time I need to spend, the use of mobile payment } \\
\text { is worthwhile to me. }\end{array}$ & MV3 & 0.89 & & & \\
\hline Overall, the use of mobile payment delivers me good value. & MV4 & 0.81 & & & \\
\hline Habit (HA) (Adapted from Limayem and Hirt [29]) & & & 0.91 & 0.78 & 0.91 \\
\hline The use of mobile payment has become a habit for me. & HA1 & 0.90 & & & \\
\hline I am addicted to using the mobile payment. & HA2 & 0.92 & & & \\
\hline I must use the mobile payment. & HA3 & 0.83 & & & \\
\hline Continued Intention to Use (CIU) (Adapted from Davis [19]) & & & 0.91 & 0.77 & 0.91 \\
\hline I will continue using mobile payment system. & CIU1 & 0.88 & & & \\
\hline I will continue using mobile payment system in the future. & CIU2 & 0.93 & & & \\
\hline I will recommend my friends to use mobile payment system. & CIU3 & 0.81 & & & \\
\hline
\end{tabular}

The model-fit indexes for the structural model provided evidence of a good model fit $\left(\chi^{2}=700.50\right.$, $\chi^{2} / \mathrm{df}=2.26, \mathrm{GFI}=0.87, \mathrm{AGFI}=0.84, \mathrm{NFI}=0.84, \mathrm{CFI}$ $=0.90$, and RMSEA $=0.065$ ).

Figure 2 displays the standardized coefficients path, path significances, and variance explained $\left(\mathrm{R}^{2}\right)$ by each path. The results showed that the mobile payment behavior was predominantly determined by mobile value $(\beta=0.45, \mathrm{p}<0.001)$ and habit $(\beta=0.18, \mathrm{p}<$ 0.01 ), supporting $\mathrm{H} 1$ and $\mathrm{H} 2$, respectively. Habit was also found to have a significant positive association with mobile value $(\beta=0.49, \mathrm{p}<0.001)$, thus supporting $\mathrm{H} 3$. The results also showed that mobile value was significantly affected by mobile convenience
( $\beta=0.38, p<0.001)$, service compatibility $(\beta=0.21, p$ $<0.01)$, security risk $(\beta=-0.15, \mathrm{p}<0.05)$, and perceived fee $(\beta=0.18, p<0.05)$. Thus, Hypotheses $1 \mathrm{a}, 1 \mathrm{~b}, 2 \mathrm{a}$, and $2 \mathrm{~b}$ were fully supported. Regarding the hypothesis tests, all paths were significant at the level of $\mathrm{p}<0.05$ or above. Hence, H1 to H4 were supported. The control variables gender, age, and frequency of mobile payment use did not have significant effects across the constructs of the research model. The variance explained (R2) of intention to use mobile payment was $42 \%$, that of mobile value was $53 \%$ and that of habit was $34 \%$. Three values exceed the cut-off value of 0.13 , which indicates a medium effect size of $\mathrm{R}^{2}$ [44]. 


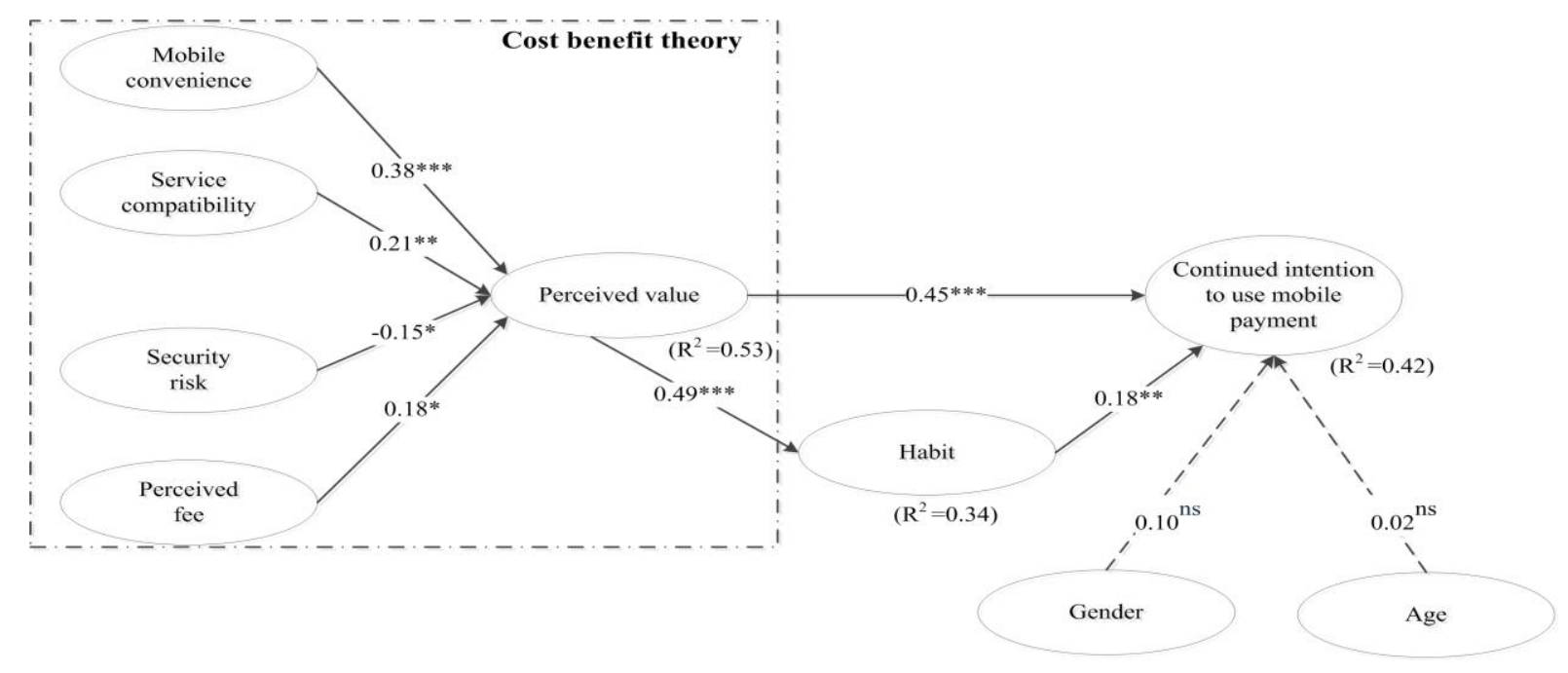

Figure 2. Structural model results (Note. $* * * p<0.001, * * p<0.01,{ }^{*} \mathrm{p}<0.05$, ns $=$ not significant)

\section{Discussion and conclusions}

This study investigates the factors that influence people's use of mobile payment within the framework of the cost benefit theory and habit. The results are discussed below.

Figure 2 shows the research results regarding users. Most important of all, being consistent with the findings of previous studies [17][25], our structural model suggests that mobile value and habit are two major factors affecting users' behavioral intention to use mobile payment. In particular, the findings indicate that mobile value is the most crucial factor affecting the behavior of mobile payment users. Mainly because of the comparison to the payment in the physical environment, the mobile payment provides service features, such as convenience, time-saving, discount and bonus [44], rendering users able to develop perceived value in mind after comparison, and further helping to bring about usage intention. The results of this study also confirm the view of scholars [6][25]. Mobile payment providers should consider whether the benefits they offer are better than the costs. That is how the providers attract more users to use the system.

With regard to the influence of users' habit on the use of mobile payments, the results are consistent with those of many studies [17][21][35], i.e. people's habit formation of information technology positively affects their behavioral intention. The results of the study show that users developed habit of using mobile payments increases their continued usage intention. In the characteristics of perceived value on benefit dimensions, both mobile convenience and service compatibility have a direct and positive impact on mobile value. Specifically, users' views on timely and convenient services of mobile payments enable them to quickly and easily complete the payment process without wasting any time, thereby enhancing their sense of mobile value. On the other hand, once a user can purchase goods, transfer accounts, and pay bills using mobile payment as they do in a physical environment, their perception of mobile value will be enhanced. These results are consistent with what have been found in the literature [24][25]. The main reason why consumers use mobile value added services is to meet their specific needs for service compatibility.

Regarding the characteristics of mobile value on cost dimensions, this study assumes that both security risk and perceived fee have a negative impact on mobile value. In terms of security risk, the findings are consistent with certain studies [11][44], which means when using mobile payment services, users pay special attention to security risk, such as leakage of personal data and records, repetitive charge, and loss of mobile phones. As for perceived fees, the results of the study show that the perceived fee has a direct and positive influence on perceived value, which the results are opposite to the hypothesis. It is assumed that due to the fact that mobile payment is able to offer users convenience by simplifying the payment procedure [44], users are more willing to pay the transaction fee to facilitate the payment procedure of the physical business environment through mobile payments.

The results of this study have several important academic implications. First, this study explores the factors that drive the user's behavior upon perception of perceived value brought about by mobile payments based on the cost benefit theory, and adds habit factors to develop an integrated model for structures. The study results suggest our research models exhibit good 
explanatory power to predict user's continued intention to use mobile payment services, providing a new direction for researchers to contemplate in subsequent research. Second, the previous studies only discussed how mobile services affected users' usage intention by means of value [6][25]. Scholars suggest that other influencing factors should be considered in addition to the value point of view in the context upon the use of information systems. Habits are a crucial factor used for interpreting and predicting users' behavior upon the use of information systems [13][15][16]. As a result, this study adds habits to fully predict the user's willingness continuing to use mobile payments. Third, this study uses the viewpoint of perceived innovation characteristics to form the part of benefit and cost components of perceived value brought by mobile payments, of which the benefit includes mobile convenience and service compatibility, while the cost includes security risk and perceived fee. These factors affect the value cognition of mobile payment services respectively. Finally, the research model has strong explanatory ability, and is able to predict the user's behavior intention to use mobile payment services. The results of the study can also be referred to for reference direction of subsequent research.

Several implications for mobile payment service practitioners can be drawn from this study. First, the results show that perceived value has a direct and significant impact on users' continued use of mobile payments, which is consistent with the findings of previous studies [6][25]. To users, the value they perceive will be formed through the function or service brought about by mobile technology. Therefore, it is excessively difficult to gain a better understanding of the formation of users' value perception without analyzing the attributes (both positive and negative) of products or services [6][9][10]. Accordingly, if the practitioner can strengthen its positive attributes, like mobile convenience and service compatibility, and reduce negative attributes, like security risks and service fees, it will help to arouse the perceived value of the user's perception, and then strengthen the continued usage intention. In addition, the results suggest that habit is one of the important factors that affect the continuous use of mobile payments. These results are in line with that of Hsiao et al.'s [17] conclusion that habit has played a very important role in the use of mobile payments. Some researchers [16][17] further pointed out that the stronger users' habit is, the less consideration of options other than existing information systems would be. Given that users have formed strong habit, their intention to continue using mobile payments will be enhanced. Finally, perceived value has a positive impact on users' habit. These results provide practitioners with important information, showing that in the mobileoriented information system context, perceived value affects users' habit of using mobile payment services if such services satisfy perceived value.

\section{Acknowledgments}

The authors thank the editor and anonymous reviewers for their comments and suggestions. This study was supported by a grant from the Ministry of Science and Technology: project number MOST-1062410-H-275-002-.

\section{References}

[1] MIC, Mobile payment developments and trends Prospects. Available from http://mic.iii.org.tw/AISP/ReportS.aspx?id= CDOC20161214001,2016.

[2] G. W. H. Tan, K. B., Ooi, S. C. Chong, and T. S. Hew, "NFC mobile credit card: The next frontier of mobile payment?", Telematics and Informatics, 31 (2), 2014, pp.292-307.

[3] T. Zeo, "An empirical examination of continuance intention of mobile payment services", Decision Support Systems, 54(2), 2013, pp.1085-1091.

[4] Statistic, Total revenue of global mobile payment market from 2015 to 2019 (in billion U.S. dollars), Available from ht tps://www.statista.com/statistics/226530/mobile-payment-tra nsaction-volume-forecast/

[5] Nielson, The modern wallet: Mobile payments are marking life easier. Available from http://www.nielsen.com/us/en/insights/news/2014/whats-inyour-wallet-mobile-payments-are-making-life-easier.html, 2014.

[6] H. W. Kim, H. C. Chan, and S. Gupta, "Value-based adoption of mobile internet: An empirical investigation", Decision Support Systems, 43(1), 2007, pp.111-126.

[7] H. P. Lu, and K. Y. Lin, "Factors influencing online auction sellers' intention to pay: An empirical study integrating network externalities with perceived value", Journal of Electronic Commerce Research, 13 (3), 2012, pp.238-254.

[8] V. A. Zeithaml, "Consumer perceptions of price, quality and value: a means-end model and synthesis of evidence", Journal of Marketing, 52(3), 1988, pp.2-22.

[9] Y. Lu, S. Yang, P. Y. K. Chau, and Y. Cao, "Dynamics between the trust transfer process and intention to use mobile payment services: A cross-environment perspective", Information and Management, 48(8), 2011, pp.393-403.

[10] H. Yang, J. Yu, H. Zo, and M. Choi, "User acceptance of wearable devices: An extended perspective of perceived value", Telematics and Informatics, 33(2), 2016, pp.256-269.

[11] H. Yang, J. Yu, H. Zo, and M. Choi, "User acceptance of wearable devices: An extended perspective of perceived value ", Telematics and Informatics, 33(2), 2016, pp.256-269. [12] E. M. Rogers, Diffusion of Innovations, Fourth ed., The Free Press, New York, 1995.

[13] M. H. Hsu, C. M. Chang, and L. W. Chuang, "Understanding the determinants of online repeat purchase 
intention and moderating role of habit: The case of online group-buying in Taiwan", International Journal of Information Management, 35(1), 2015, pp.45-56.

[14] M. Limayem, and C. M. K. Cheung, "Understanding information systems continuance: the case of Internet based learning technologies", Information and Management, 45(4), 2008, pp.227-232.

[15] M. Limayem, S. G. Hirt, and C. M. K. Cheung, "How habit limits the predictive power of intention: the case of information systems continuance", MIS Quarterly, 31(4), 2007, pp.705-737.

[16] J. Y. Lai, and J. Wang, "Switching attitudes of Taiwanese middle-aged and elderly patients toward cloud healthcare services: An exploratory study", Technological Forecasting \& Social Change, 92, 2015, pp.155-167.

[17] C. H. Hsiao, J. J. Chang, and K. Y. Tang, "Exploring the influential factors in continuance usage of mobile social APPs: Satisfaction, habit, and customer value perspectives", Telematics and Informatics, 33(2), 2016, pp.342-355.

[18] A. P. Oghuma, C. F. Libaque-Saenz, S. F. Wong, and Y. Chang, "An expectation-confirmation model of continuance intention to use mobile instant messaging", Telematics and Informatics, 33(1), 2016, pp.34-47.

[19] F. Davis, "Perceived usefulness, perceived ease of use, and user acceptance of information technology", MIS Quarterly, 13(3), 1989, pp.319-340.

[20] V. Venkatesh, M. G. Morris, G. B. Davis, and F. D. Davis, "User acceptance of information technology: toward a unified view", MIS Quarterly, 27(3), 2003, pp.425-478.

[21] G. Baptista, and T. Oliveira, "Understanding mobile banking: The unified theory of acceptance and use of technology combined with cultural moderators", Computers in Human Behavior, 50(1), 2015, pp.418-430.

[22] H. Kim, I. Lee, and J. Kim, "Maintaining continuers vs. converting discontinuers: relative importance of postadoption factors for mobile data services", International Journal of Mobile Communications, 6(1), 2008, pp.108-132.

[23] T. Zhou, Y. Lu, and B. Wang, "Integrating TTF and UTAUT to explain mobile banking user adoption", Computers in Human Behavior, 26 (4), 2010, pp.760-767.

[24] M. H. P. Kleijnen, J. C. de Ruyter, and M. G. M. Wetzels, "An assessment of value creation in mobile service delivery and the moderating role of time consciousness", Journal of Retailing, 83(1), 2007, pp.33-46.

[25] K. Y. Lin, and H. P. Lu, "Predicting mobile social network acceptance based on mobile value and social influence", Internet Research, 25(1), 2015, pp.107-130.

[26] R. N. Bolton, and J. H. Drew, "A multi-stage model of customer's assessments of service quality and value", Journal of Consumer Research, 17(4), 1991, pp. 375-384.

[27] S. C. Chen, and C. P. Lin, "The impact of customer experience and perceived value on sustainable social relationship in blogs: An empirical study", Technological Forecasting \& Social Change, 96(1), 2015, pp.40-50.

[28] H. Aarts, T. Paulussen, and H. Schaalma, "Physical Exercise Habit: On the Conceptualization Formation of Habitual Health Behaviours", Health Education Research, 12(3), 1997, pp.363-374.

[29] M. Limayem, and S. G. Hirt, "Force of habit and information systems usage: Theory and initial validation",
Journal of the Association for Information Systems, 4(1), 2003, pp.65-95.

[30] D. J. Kim, and Y. Hwang, "A study of mobile internet user's service quality perceptions from a user's utilitarian and hedonic value tendency perspectives", Information Systems Frontiers, 4(2), 2010, pp.63-84.

[31] C. Wang, "Antecedents and consequences of perceived value in Mobile Government continuance use: An empirical research in China", Computers in Human Behavior, 34(1), 2014, pp.140-147.

[32] M. L. Meuter, M. J. Bitner, A. L. Ostrom, and S. W. Brown, "Choosing among alternative service delivery modes: an investigation of customer trial of self-service technologies", Journal of Marketing, 69(2), 2005, pp. 61-83.

[33]MIC, Current Status of the mobile payment in Taiwan and its Future Development, 2015. Available from http://mic.iii.org.tw/AISP/ReportS.aspx?id=CDOC20151217 005.

[34] Merriam-Webster, Fee Dictionary, The MerriamWebster, 2012. Available from http://www.merriamwebster.com/dictionary/fee

[35] S. Nikou, and H. Bouwman, "Ubiquitous use of mobile social network services", Telematics and Informatics, 31(3), 2014, pp.422-433.

[36] M. C. Lee, "Factor influencing the adoption of internet banking: an integration of TAM and TPB with perceived risk and perceived benefit", Electronic Commerce Research and Applications, 8(3), 2009, pp.130-141.

[37] P. Luarn, and H. H. Lin, "Toward an understanding of the behavioral intention to use mobile banking", Computers in Human Behavior, 21(6), 2005, pp.873-891.

[38] J. C. Nunnally, Psychometric Theory, McGraw Hill, New York, NY, 1978.

[39] C. Fornell, and D. F. Larcker, "Evaluating structural equation models with unobservable variables and measurement error", Journal of Marketing Research, 18(1), 1981, pp. 39-50.

[40] R. P. Bagozzi, and Y. Yi, "On the evaluation of structural equation models", Journal of Academy of Marking Science, 16(2), 1988, pp. 74-94.

[41] L. A. Hayduck, Structural equation modeling with LISREL. Baltimore, MD: Johns Hopkings University Press, 1987.

[42] J. Scott, "The measurement of information systems effectiveness: Evaluating a measuring instrument", In Proceedings of the Fifteenth International Conference on Information Systems, Vancouver, BC, 1994, pp.111-128.

[43] P. M. Bentler, and D. G. Bonett, "Significant Tests and Goodness of Fit in the Analysis of Covariance Structures", Psychological Bulletin, 88 (3), 1980, pp.588-606.

[44] J. Cohen, Statistical power analysis for the behavioral sciences. Hillsdale, NJ: Lawrence Erlbaum Associates, 1988. [45]MIC, Mobile payment consumer analysis survey. Availa ble from http://mic.iii.org.tw/AISP/ReportS.aspx?id=CDOC2 $0170123004,2017$. 